NASA/CR—1998-208678

\title{
Destructive Evaluation of a Xenon Hollow Cathode After a 28,000 Hour Life Test
}

Timothy R. Sarver-Verhey

Dynacs Engineering Company, Inc.

Prepared for the

34th Joint Propulsion Conference and Exhibit cosponsored by AIAA, ASME, SAE, and ASEE

Cleveland, Ohio, July 13-15, 1998

Prepared under Contract NAS3-98008

National Aeronautics and

Space Administration

Lewis Research Center 


\section{Acknowledgments}

The author would like to acknowledge the technical support of F.K. Jent, J.R. Miller, G.R. Schneider, R.D. Buttler, C.D. Schroeder, J.B. Naglowsky, R.A. Jacko, E. Theman, and J.E. Parkes in execution of this life test.

Additionally, the efforts of T. Leonhardt, J. Sweeney, and R. Garlich, are acknowledged for their technical support during the destructive analyses activities.

Available from

NASA Center for Aerospace Information

7121 Standard Drive

Hanover, MD 21076

Price Code: A03
National Technical Information Service 5285 Port Royal Road Springfield, VA 22100

Price Code: A03 


\title{
Destructive Evaluation of a Xenon Hollow Cathode After a 28,000 Hour Life Test
}

\author{
Timothy R. Sarver-Verhey \\ Dunacs Engineering Co., Inc. \\ NASA Lewis Research Center Group \\ Brook Park, $\mathrm{OH} 44142$
}

The International Space Station (ISS) plasma contactor system requires a hollow cathode assembly (HCA) with a lifetime of at least 18,000 hours. In order to demonstrate the lifetime capability of the HCA, a series of hollow cathode wear tests was performed which included a life test operated at the maximum current of the HCA. This test sought to verify hollow cathode lifetime capability and contamination control protocols. This hollow cathode accumulated 27,800 hours of operation before it failed during a restart attempt. The cathode was subsequently destructively analyzed in order to determine the failure mechanism. Microscopic examination of the cathode interior determined that relatively small changes in the cathode physical geometry had occurred and barium tungstates, which are known to limit the emission process, had formed over a majority of the electron emitter surface. Because the final state of the insert was consistent with expected impregnate chemistry, the hollow cathode was believed to have reached the end of its usable life under the test conditions.

\section{Introduction}

A plasma contactor with a xenon hollow cathode assembly (HCA) has been baselined for the International Space Station (ISS). 'The plasma contactor will provide a connection from station structure to the surrounding space plasma and alleviate the build-up of electrical charge on the ISS. ${ }^{\prime}$ Operational requirements for the HCA are to provide an electron emission current of up to $10 \mathrm{~A}$ and a life of 18,000 hours. ${ }^{2}$ In order to meet these HCA requirements, a reliable, long-life hollow cathode and electron emitter are needed.

While there is experience using hollow cathodes with mercury, ${ }^{3.4}$ the number of life tests performed with xenon is small, particularly with regards to operation at high currents $(>1 \mathrm{~A}) .^{5-11}$ In addition, there have been several instances of performance degradation and cathode failure, ${ }^{1-8.12-14}$ and none has met the requirements for the ISS HCA.

Consequently, a hollow cathode test program was initiated at the NASA Lewis Research Center to resolve life-limiting problems. The primary cause believed responsible for degradation was oxygen contamination of the electron emitter surface. To address the contamination, control protocols were implemented and gas feed system fidelity was improved. ${ }^{x}$ These changes resulted in improved hollow cathode performance and reduced degradation of the emitter surfaces, as demonstrated by the successful completion of multiple hollow cathode wear tests ${ }^{x . y}$ and the on-going life tests of several development model HCAs. ${ }^{1 "}$

A life test of a xenon hollow cathode was performed to demonstrate contamination control via incorporation of all previously developed protocols and the $18.0(0)$ hour ISS lifetime requirement with margin. The hollow cathode was successfully operated for 27,800 hours at an emission current of $12 \mathrm{~A}$ before the test was terminated due to changes in operating characteristics. Details on the eathode performance during the life test have been reported previously..$^{\text {s }}$ A brief summary of the test apparatus and performance will be included in this report.

Destructive analyses of the hollow cathode and test systems were performed to determine the cause of the cathode failure. The analysis procedures. results. and discussion of the critical mechanisms will be presented in this report.

\section{Apparatus and Procedures}

\section{Hollow Cathode}

The hollow cathode, shown in Figure 1, consisted of a refractory metal tube with a plate welded to one end. The plate has a small orifice with a chamfer on the downstream surface. An electron emitter that was comprised of a porous sintered tungsten cylinder impregnated with barium-containing compound was secured in the downstream end of the tube.

A sheathed heater ${ }^{1 /}$, used for conditioning and ignition, was fitted on the outside of the cathode tube over the region occupied by the electron emitter. Several layers of metal foil were wrapped around the heater to reduce radiated power losses.

This hollow cathode was functionally and materially similar to that used in the development and flight model HCAs. - While there were minor mechanical differences including the orifice diameter and heater geometry, none of these differences invalidate the applicability of the test results. In part, the differences were due to the fact that this life test was initiated more than one year before the HCA design was completed.

\section{Test Configuration, Condition, and Procedures}

The life test was performed in a diode configuration with a planar anode mounted approximately $6 \mathrm{~cm}$ downstream of the hollow cathode. Information pertaining to test configuration, feed system design. power 
supplies, and instrumentation was provided in earlier reports. ${ }^{15.17}$

The life test was conducted at an emission current of $12 \mathrm{~A}$ and a xenon flow rate of approximately $4.2 \mathrm{sccm}$. The current was selected because it was estimated at that time to be the maximum required emission current for the HCA and thus represented a conservative operating point. The xenon flow rate was selected because it was the minimum value, with margin, that this cathode operated at stably during a pre-test characterization.

Procedures relating to feed system preparation and instrument calibration used in the life test were discussed in detail in earlier reports. ${ }^{15.17}$ The ignition procedure used for this hollow cathode will be described briefly. The cathode was heated to high temperature for a fixed period after which an increasing DC voltage was applied between the hollow cathode and the planar anode until discharge breakdown occurred. The breakdown voltage was used as an indicator of cathode condition. The conditioning and ignition procedures used for this hollow cathode differ from those used for the development model and flight $\mathrm{HCAs}^{2}$ because this life test was initiated before refined procedures were established for the HCA.

\section{Life Test Performance}

The life test was initiated on December 30, 1992, and terminated on May 2, 1997. During the life test, the cathode accumulated 27,800 hours (3.2 years) of operation. exceeding its target of 18,000 hours. The behavior of operating parameters of interest are compiled in Table 1. These include the initial, mean, maximum, minimum, and final values of anode voltage, cathode temperature, and xenon flow rate.

Hollow cathode performance during the life test was analyzed by monitoring the anode voltage, cathode temperalure, and ignition voltages. The anode voltage was measured at the vacuum flange with a digital voltmeter. The anode voltage was relatively stable with a mean value of $12.9 \mathrm{~V}$. Figure 2 shows the behavior of the anode voltage as a function of test time. There were two types of voltage variations observed: 1) slow oscillation in magnitude that occurred over a period of several thousand hours, and 2) daily voltage variations of approximately $\pm 0.3 \mathrm{~V}$ that resulted from changes in xenon flow rate of approximately $\pm 0.2 \mathrm{sccm}$ caused by ambient laboratory temperature changes. The anode voltage stability was maintained in part by slight increases in xenon flow rate between hours 16,700 and 23.300 that occurred because the indicated flow was suspect and the flow rate was being maintained by monitoring indirect parameters.

The cathode tip temperature, measured with a disappearing filament pyrometer, is shown in Figure 3 as a function of test time. The temperature exhibited two changes during the life test. The temperatures all decayed continually until approximately hour 23,000 , at which tine the temperatures started to rise relatively rapidly. This second change lasted until approximately hour 23,776 when the test was stopped when the cathode exceeded a pre-specified maximum value of 1,350 ${ }^{\circ} \mathrm{C}$. The cathode brightness temperature of $1,350{ }^{\circ} \mathrm{C}$ was established as a shut-down criterion to ensure that the condilion of the hollow cathode and electron emitter were preserved against rapid changes due to operation at excessive temperature. The life test was resumed after no test support equipment-related cause for the elevated temperature could be identified. The cathode tip temperature subsequently stabilized at approximately $1,315^{\circ} \mathrm{C}$ and remained there for approximately 4,000 hours. The tip temperature then exceeded the $1,350^{\circ} \mathrm{C}$ limit at approximately hour 27,795 .

The ignition voltage over the course of the life test is shown in Figure 4. As can be seen, prior to the restart at 23,776 hours, the ignition voltage increased from approximately 42 to 62 VDC. However, at hour 23,776 , the ignition voltage increased significantly to approximately 725 VDC. The ignition voltage continued to increase over the remainder of the life test. By hour 27,800 , the ignition voltage required for breakdown exceeded the maximum of 1050 VDC that was available rom the ignitor power supply.

End-of-Life Test Behavior Life testing of the hollow cathode was discontinued at hour 27,800 when the cathode failed to ignite with an applied voltage of 1050 VDC. Testing had been interrupted at hour 27,795 when the xenon flow decreased below the set-point which resulted in a limit violation on the anode voltage. The cathode was subsequently reignited, but required $1046 \mathrm{VDC}$ along with a slight increase ( $2 \%)$ in heater power. Because the cathode operated in excess of 1,350 ' $\mathrm{C}$ during the subsequent performance characterization and brief steady-state period, it was shut down. A that time, the cathode had accumulated 27,800 hours. A subsequent ignition attempt failed to ignite the cathode at the maximum ignition voltage of 1,050 VDC after a period of approximately 10 minutes.

Rather than attempt ignition by increasing ignition voltage al d heater power, it was decided to discontinue the life te;t to preserve the cathode emitter from potential rapid changes during operation at elevated temperatures.

\section{Destructive Post-test Analysis - Observations and Discussion}

Post-te: 1 evaluation of the hollow cathode was performed to determine the changes to the cathode condition responsible for changes in operation. The cathode and electron emitter were examined with optical and electron microscopes to document the physical 
conditions. Secondary (SE) and Backscattered Electron (BSE) Emission Imaging in the Scanning Electron Microscope (SEM) were used for elemental characterization. Energy Dispersive X-Ray Spectroscopy (EDS) was also used in the SEM for elemental determination. X-Ray Micro-diffraction Analysis (XRMA) was used to identify compounds on the electron emitter surface. Additionally, a portion of the cathode tip was prepared metallographically for microscopic examination of bulk characteristics.

The critical features of the hollow cathode which impact cathode operation were the cathode orifice plate and the electron emitter. Additionally, the cathode tube, heater, and test facility were examined to determine if they contributed to cathode failure. The changes in each of these features will be discussed below as well as summarized in Table 2.

\section{Observations}

\section{Cathode Orifice Plate}

While several features of the cathode orifice plate, including orifice surface and channel and the plate-tube joint, exhibited small physical changes, none of the changes limited the cathode performance or contributed to its failure. Additionally, the phenomena described in this section have been observed in several previous hollow cathode wear and life tests: . $^{5.14}$

Exterior Surface Figures 5(a) and (b) show the preand post-test appearance of the cathode orifice plate exterior surface. The orifice plate exhibits distinct erosion of the surface. While the general shape of the cathode tube-orifice plate joint is visible, it is apparent that material has been removed in this area. Additionally, the erosion smoothed the orifice chamfer and channel edges.

Orifice Plate-Cathode Tube Joint The orifice plate-tube joint was not compromised during the test. Examination of the final condition of the electron-beam weld showed that it was intact and did not lose a significant amount of material due to surface erosion.

Interior Surface The interior surface of the orifice plate experienced erosion as well as tungsten deposition. From the micrograph shown in Figure 6, there is a significant deposition of tungsten that is greatest at the orifice edge and decreases in amount of material further away from the edge. In addition, the cross-section of the orifice tip, shown in Figure 7, indicates that material has been removed from the plate itself. Tungsten deposits built up on the eroded region and extended approximately $230 \mu \mathrm{m} \pm 15 \mu \mathrm{m}\left(0.009^{\prime \prime} \pm 0.0006^{\prime \prime}\right)$ from the original plate surface. While deposition of tungsten material at the orifice plate has been seen in past wear and life tests ${ }^{5-8}$, an explanation for the erosion and its relationship to the tungsten deposition cannot be offered at this time.
Figure 6 also shows the region of the orifice plate which the insert occluded. A layer of material was found in this region composed of the impregnate components and tungsten. with trace signals of Mo and Re. The impregnate-based material was believed to have come from the insert during testing.

Orifice Plate Thickness The orifice plate thickness was found to have decreased by $\leq 6 \%$, uniformly across its diameter, as can be seen in Figure 7. The uniformity of the plate thickness suggests that negligible material removal occurred, even though the exterior orifice surface exhibited texturing by erosion, as seen in Fig. 5(b).

Orifice Diameter The final pass-through diameter of the cathode orifice increased by approximately $14 \%$ $\pm 2 \%$ during the life test. The orifice diameter was measured with a pin tool and photographically (after metallographic preparation). The second technique showed that the narrowest dimension of the orifice was at the upstream end of the orifice channel.

The increased orifice diameter was believed to have caused the anode voltage to become more sensitive to flow rate variations. The flow rate subsequently was increased slightly so that the anode voltage remained relatively stable under the daily flow rate variations. Over the course of the life test, the flow rate was increased by approximately $11 \%$. The change in diameter is consistent with the required increase in xenon flow rate to maintain stable spot mode operation, according to criteria established by Kaufman. ${ }^{15}$

Orifice Channel Immediately downstream of the minimum orifice diameter, the orifice channel diameter increased by approximately $26 \%$ (over the original orifice diameter), as shown in Fig. 7. The channel diameter continues to increase with proximity to the downstream end to a maximum of $29 \%$ (over the orig $\mathrm{i}$ nal diameter) at the base of the chamfer. Similar changes to the orifice channel have been observed in other life tests. ${ }^{1 *}$

Orifice Chamfer The final orifice chamfer was changed slightly by the erosion of the edges of the chamfer as shown in Fig. 7. The changes in these edges made it difficult to quantify the chamfer angle. but qualitatively the chamfer was wholly intact.

\section{Cathode Assembly}

There were some observed changes to the hollow cathode that did not impact lifetime.

Cathode Tube The exterior surface of the cathode tube developed a porous (sponge-like) formation, as seen in Figure 8. The cross-section, shown in Fig. 7. indicated that the porous structure extended into the tube wall to depths of up $100.17 \mathrm{~mm}$. This porous structure appears to extend at least $6.3 \mathrm{~mm}$ upstream of the orifice plate, which is well into the area covered by the heater. The porous formation was examined via EDS which indicated that the amount of Mo in the porous region was reduced by approximately one-half 
relative to the $\mathrm{Re}$ content. The cause of this apparent removal of the Mo is presently unknown. The porous structure did not compromise the tube strength which was found to be intact during the post-test destructive analyses.

Cathode heater The radiation foil of the cathode heater experienced severe erosion during the life test. The final condition is partially shown in Fig. 5(b). The downstream end of the foil was eroded until most of the first heater coil was exposed. Additionally, the outermost layer of the foil detached during removal of the cathode from the test facility. The erosion also occurred on the upstream end of the heater. The sheath material appeared intact (i.e. no exposure of the $\mathrm{MgO}$ ). Despite the erosion, the remaining radiation foil appears to be firmly attached to the heater.

The radiation foil erosion is the result of its exposure to the discharge environment during the life test and is peculiar to this test configuration. This erosion is not observed in the HCA after life testing because the anode shell encloses the cathode tube."

\section{Electron Emitter (Insert)}

The final state of the insert was examined extensively to document the physical and chemical changes. The observations are shown graphically in Figure 9 and described below.

Tungsten Deposition At the downstream end of the insert, a tungsten deposition layer was observed. This formation extend approximately $2 \mathrm{~mm}$ upstream of the orifice plate, had an irregular upstream border, and extended to a height of approximately $110 \mu \mathrm{m} \pm 10$ $\mu \mathrm{m}$. This formation was composed entirely of tungsten grains approximately $50 \mu \mathrm{m}$ in diameter. An edge view of a portion of this deposition is shown in Figure 10.

There were other regions of tungsten deposition further upstream on the insert surface, but these depositions tended to be single metallic crystals or small tungsten particles lying on the insert surface, unattached to the matrix tungsten. A formation mechanism for the tungsten depositions is discussed later in the report.

Ba-containing layer formations Nearly continuous Ba-containing layers were present on approximately $70 \%$ of the upstream end of the insert. An example of these layers is shown in Figure 11. The composition of the layers varied with position, with $\mathrm{Ba}$ and $\mathrm{W}$ being the primary elements and $\mathrm{Ca} . \mathrm{Al}$, and $\mathrm{O}$ also present in reduced and varying amounts. XRMA (X-Ray Microdiffraction Analysis) identified two forms of barium tungstate as the primary constituents of these layers. First $\left.\mathrm{Ba}_{2} \mathrm{CaW(}\right)_{6}$ formations were dominant starting at $6.3 \mathrm{~mm}$ from the downstream end of the insert to 7.6 $\mathrm{mm}$ from the downstream end. At this point, the second tungstate, $\mathrm{BaWO}$, became prevalent in the surface formations and was the dominant tungstate starting at approximately $10 \mathrm{~mm}$ from the downstream end.
$\mathrm{BaWO}_{4}$ uas the primary tungstate formation on the remainder of the upstream end of the insert, with a minor $\mathrm{Ba}_{2} \mathrm{CaWO}_{6}$ component in that region.

The morphology of these layers was relatively constant over the surface. The thickness of the layers increased along the emitter length, from approximately 5 $\mu \mathrm{m}$ thick at $7.6 \mathrm{~mm}$ from the downstream end to approximately $90 \mu \mathrm{m}$ at the upstream end. A crosssection of the layer at the upstream end is shown in Figure 12.

Besides the layer formations, Ba-based coatings were observed on some of the downstream surfaces of the cathode interior. These coatings varied from isolated spots of material to relatively complete coverage of the matrix grains. These coatings differed from the layers discussed above primarily in that the underlying tungsten matrix grains were visible.

Internal Ba content An investigation was performed to determine the amount of Ba-containing compound(s) remaining in the electron emitter. However, while copious amounts of $\mathrm{Ba}$ were detected within the emitter material, the composition or distribution of the interior Ba-containing compounds (in particular the compounds that lock up the $\mathrm{Ba}$, including tungstates and aluminates) could not be determined.

The observed changes in the electron emitter condition are believed to be critical to the cathode performance and lifetime and are discussed further below.

\section{Feed System}

Feed System Integrity Maintaining feed system integrity was critical to preventing oxygen contamination of the insert. A pressure rate-of-rise standard was used repeatedly to verify the feed system integrity throughout the life test following any changes to the feed systein (xenon bottle change-outs, flowmeter calibration, etc.). While there were instances where the feed systen failed to meet the rate-of-rise specification, gas sampl ng of the gas after the worst case found that the xenon reaching the cathode was still within the xenon conta nination specification. ${ }^{2}$ Consequently, feed system clianliness was acceptable throughout the life test.

Gas Purifier The life test was initiated with a gas purifier in the system in order to maintain the lowest possible oxygen contamination. The purifier was capable of purfying xenon to a level of $10 \mathrm{ppb}$ of oxygencontaining contaminants, at a maximum inlet gas contamination of $15 \mathrm{ppm}$. The gas purifier was removed from the $f$ :ed system at hour 23,779 because the downstream isclation valve of the purifier had failed. Since there was at least one instance of direct atmospheric exposure during a feed-system rebuild, the purifier was suspected of being depleted. The purifier was subsequently destructively examined by the manufacturer. The downstream valve was found to have failed in-line only (therefore no atmospheric exposure during 
testing) and only $5 \%$ of the purification media was found to have been used. ${ }^{14}$ Therefore, the purifier was functional up to the time of its removal and the hollow cathode changes observed prior to its removal are not apparently related to its condition.

\section{Discussion of Observations}

The hollow cathode life test was ended because the cathode exceeded the maximum temperature of 1,350 ${ }^{\circ} \mathrm{C}$ and could not be ignited at the maximum available ignition voltage. The observed changes suggested that the cathode insert condition was evolving and consequently could no longer perform sufficiently within the defined operating envelope. The changes in the cathode interior believed critical to lifetime were tungsten deposition, Ba-containing layer formation, and tungstate/aluminate formation.

\section{Life-Limiting Phenomena}

Tungsten Deposition Deposition on the orifice plate interior and downstream end of the electron emitter, as shown in Figs. 6 and 10, is believed to result from the condensation of free metallic tungsten onto these surfaces. Based on the observations on this cathode and others, the following process for free metallic tungsten formation and deposition is hypothesized to take place.

1. Matrix tungsten from the insert reacts with oxygen released from the impregnate or matrix tungsten during cathode operation.

2. The resulting tungsten oxides will then volatilize off the insert surface at operating temperatures.

3. The oxides join the relatively quiescent cathode interior atmosphere and are then dissociated into free tungsten and oxygen. A possible mechanism for this dissociation is energetic collisions in the emission region.

4. The free metallic tungsten will then collect on the cooler surfaces of the insert and cathode interior.

The consequences of the tungsten deposition depend on where it occurs on the electron emitter surface. The tungsten is believed to condense at locations away from the emission region, which is typically smaller than the emitter surface area. ${ }^{20}$ Deposition at the downstream end is expected to occur after the emitter material in this region has evolved such that it can no longer readily produce free barium. The emission will then move upstream to lower work function regions. The downstream region will then be slightly cooler and the metallic tungsten can collect into stable crystalline formations of varying magnitudes, from whiskers to larger crystals. Since the emitter material is believed to have changed, continued deposition at the downstream end is not expected to impact cathode operation until it begins to physically obstruct the discharge.

At the upstream end and outside the emission region, deposited tungsten can react with available barium and oxygen on the emitter surface. $\mathrm{Ba}$ and $\mathrm{O}$ are present on the surface because the relatively high operating temperature is sufficient to drive the $\mathrm{Ba}$ release process over much, if not all, of the emitter surface. However, there is no significant removal mechanism for these elements since the emission region is downstream of this area. Deposition at the upstream end will have a significant impact on the cathode performance because the deposited tungsten is likely to react with the surface materials over time, rather than form crystalline deposits. The reaction products are expected to degrade the emission capability of the surface by inhibiting the low work function surface formation. ${ }^{22.23}$

Ba-Containing Layer/Tungstate Formation The presence of the tungstate-predominant layers on approximately $70 \%$ of the upstream end of the insert surface indicates that this region will not emit properly at the test conditions. Monobarium tungstate $\left(\mathrm{BaWO}_{4}\right)$ will be completely inert at the cathode operating temperature and it is unclear at this time if the $\mathrm{Ba}_{2} \mathrm{CaWO}_{6}$ will continue to react in a way that supports the work function lowering process. ${ }^{21.22}$

These layers are believed to be formed when $\mathrm{Ba}$ and other elements released from the impregnate in the emission region collected at cooler locations on the insert surface. In addition, the deposited tungsten discussed above is expected to contribute to the formation of these layers. Since these collection regions are outside the emission zone, there is no significant mechanism for permanent removal of the material. The configuration of the hollow cathode and the presence of a relatively high pressure atmosphere in the region of the electron emitter will also enhance the insert surface chemistry. Once collected, the Ba and other deposited material will react with elements in the collection area. At the elevated temperatures of the insert, the elements will eventually evolve into barium tungstates and aluminates, of which $\mathrm{BaWO}_{4}$ is the most stable form. The formation of these tungstates are expected under normal emitter operation. ${ }^{22}$

In traditional dispenser cathodes, any material released from the surface, will migrate quickly away from the insert and condense on the much cooler surfaces surrounding the insert. ${ }^{23}$ Consequently the formation of the tungstates are expected to be significantly reduced.

Because the barium tungstate layers will not perform as low-work function surfaces at the life test temperatures, the emission will be degraded. Because of the complexity of the composition of the upstream surface and lack of reaction rate data on emitter surface chemistry, particularly in the hollow cathode configuration. the degradation process of this region cannot he quantified at this time. 
Barium Content in Insert While copious amounts of elemental barium were found throughout the electron emitter matrix, the amount available for the discharge process remains unknown. It is expected that a portion of the $\mathrm{Ba}$ will be in tungstate or aluminate compounds as part of the normal impregnate chemistry. These compounds can eventually reduce the $B$ a release rate and subsequently impact the distribution of the workfunction reducing chemistry. Significant formations of the inert tungstate and aluminate compounds are suspected to be present in the downstream end of the insert. where the lungsten deposition took place. Addilionally, free Ba may be unable to reach the emitter surface because it would be trapped by the barium tungstate layers formed on the upstream surface of the insert.

\section{Drivers of Life-Limiting Phenomena}

The electron emitter chemistry indicated by the observed surface formations suggest that the formations of the tungstates were the primary factor resulting in the cathode heing unable to operate properly. The driver mechanisms for the tungstate formation are believed to be oxygen availability and insert temperature.

Oxygen Availability There are two possible sources for oxygen that can react at the insert surface. These are contamination of the gas upstream of the cathode and oxygen release from the insert impregnate and sintered tungsten matrix.

While oxygen contamination could have theoretically occurred from contaminated xenon or leaks in the feed system, there is no evidence that this occurred. Under the worse case analysis, the amount of oxygen that could have been released from the feed system was less than that released from the emitter. Since no gross chemical or physical changes or unique phenomena were observed, and the observed phenomena are consistent with known emitter chemical processes ${ }^{23}$, the total amount of oxygen at the surface likely does not exceed that released by the emitter.

There is a significant amount of oxygen available within the impregnate, which is released during the normal decomposition of the impregnate at high temperature. ${ }^{23.24}$ Additionally, it has been estimated that $200-300) \mathrm{ppm}$ of oxygen is trapped in the sintered tungsten during fabrication ${ }^{23}$, which will contribute to the chemical reactions in the emitter. While these sources of oxygen are an issue for all types of dispenser cathodes, in a hollow cathode, the oxygen will be contained within the electron emitter region because of the hollow cathode geometry and interior pressure. Consequently, oxygen release from within the bulk material and reaction at the insert surface is an inherent part of the impregnate decomposition process within the hollow cathode.
Temperature The chemistry taking place in and on the electron emitter is driven by the material temperature. This chemistry includes both the $\mathrm{Ba}$ release to lower the surface work function as well as the formation of barium tungstates. It is not possible for the emitter to function properly without forming the lifelimiting barium tungstates as a reaction product of the impregnate chemistry. ${ }^{22}$ Only the rate of the reactions can be controlled by changes in the emitter temperature.

While the cathode life test temperatures imply that the emitter temperature exceeded the recommended limit of $1,150^{\circ} \mathrm{C}$ for this impregnated material,, 3.25 the hollow cathode accumulated nearly 28,000 hours of operation. Since no gross or unique changes were observed on the electron emitter surface that indicate excessive temperature or oxygen contamination, the final condition of the cathode is taken to be the emitter endof-life. The formation of the tungstate-containing layers is believed to be responsible for the degraded cathode operation, because these compounds are inert at the test temperature. The tungstates could provide $\mathrm{Ba}$ for work function reduction and enable further operation of the cathode if the emitter temperature had been increased. ${ }^{23}$ However, such an increase would require changes in the operating conditions. Therefore, for a hollow cathode of this configuration and operated at these contlitions, the maximum lifetime capability is approxima tely 28,000 hours.

\section{Concluding Remarks}

To demonstrate lifetime, a hollow cathode was tested in a diode configuration at a $12 \mathrm{~A}$ emission current for 27,800 hours; the longest reported test of a high-current xenon hollow cathode to date, exceeding the test objective of 18,000 hours. The test ended when the cathode could no longer operate within the nominal test conditions. The cathode was subsequently destructively analyzed. Microscopic examination found relatively small changes in the cathode geometry and extensive chemistry on the electron emitter surface. Barium tungstates wer: detected over much of the electron emitter surface. T tese tungstates are inert at the life test conditions and therefore are believed to be responsible for ending tht life test. No external factors were identified which cot ld have accelerated the tungstate formation thereby ctiusing the cathode to fail prematurely. The observed shemistry on the emitter surface is believed to be a normal consequence of the impregnate chemistry at the life test conditions. Consequently, for this hollow caihode configuration at this operating condition, the 1 fetime of 27,800 hours is believed to be the maximum duration that can be expected. 


\section{References}

${ }^{1}$ Patterson, M.J., et al., "Plasma Contactor Technology for Space Station Freedom," AIAA Paper 93-2228. June 1993.

2 Patterson, M.J., et al., "Space Station Cathode Design, Performance, and Operating Specifications," NASA/TM-1998-206529, May 1998.

${ }^{3}$ Collett. C., "Thruster Endurance Test," NASA CR135011, May 1976.

+ Bechtel, R.T., Trump. G.E., and James, E.J., "Results of the Mission Profile Life Test," AIAA Paper 821905, Nov. 1982.

"Patterson, M.J. and Verhey, T.R., "5-kW Xenon Ion Thruster Life-test." AlAA Paper 90-2543, July 1990.

"Sarver-Verhey, T.R. and Patterson, M.J., "Microanalysis of Extended-Test Xenon Hollow Cathodes," AIAA Paper 91-2123, June 1991.

${ }^{7}$ Brophy, J.R. and Garner, C.E., "A 5,000 hour Xenon Hollow Cathode Life Test," AIAA Paper 91-2122, June 1991.

* Sarver-Verhey, T.R., "Extended-Testing of Xenon Ion Thruster Hollow Cathodes," NASA CR-189227. July 1992.

"Soulas, G.C., "Multiple Hollow Cathode Wear Testing for the Space Station Plasma Contactor," NASA CR-195357, July, 1994.

1" Soulas, G.C. and Sarver-Verhey, T.R., "International Space Station Cathode Life Testing," NASA/CR-97206230, Nov. 1997.

"Polk, J.E., et al., "The Effect of Engine Wear on Performance in the NSTAR 8000 Hour Ion Engine Endurance Test," AIAA Paper 97-3387. July 1997.

12 Beattie, J.R., Matossian, J.N., and Robson, R.R., "Status of Xenon Ion Propulsion Technology," AIAA Paper 87-1003, May 1987.

13 Brophy, J.R. and Garner, C.E., "Tests of High Current Hollow Cathodes for Ion Engines," AIAA Paper 88-2913, July 1988.

${ }^{14}$ Rawlin, V.K., "Internal Erosion Rates of a $10 \mathrm{~kW}$ Xenon Ion Thruster," AIAA Paper 88-2912, July 1988.

15 Sarver-Verhey. T.R.. "28.000 Hour Xenon Hollow Cathode Life Test Results," NASA/CR-97-206231, Nov. 1997.

1t Soulas, G.C., "Hollow Cathode Heater Development for the Space Station Plasma Contactor," IEPC Paper 93-042, September 1993.

${ }^{17}$ Sarver-Verhey, T.R., "Continuing Life Test of a Xe" non Hollow Cathode," NASA CR-195401, Nov. 1994.

1* Rawlin, V.K., "A 13,000-Hour Test of a Mercury Hollow Cathode," NASA TM X-2785, June 1973.

1" Kim, J., Semi-Gas Systems, Official Communication, 12.11 .97

24) Siegfried, D.J. and Wilbur, P.J., "Studies on an Experimental Quartz. Tube Hollow Cathode," AIAA Paper 79-2056, 14th IEPC, Oct. 30-Nov. 1, 1979.

${ }_{21}$ Ohlinger, W., Westinghouse/Betis Lab., Personal Communication. 02.26.98.
22 Suitch, P.R., "Thermochemical Reactions in Tungsten-Matrix Dispenser Cathodes Impregnated with Various Barium-Calcium-Aluminates," Thesis report. Georgia Institute of Technology. December, 1987.

23 Ohlinger, W., Westinghouse/Betis Lah., Personal Communication, 01.30.98.

24 Longo, R.T., Hughes Aircraft Company. Personal Communication, 02.06 .98

${ }^{25}$ Kohl, W.H., Handbook of Materials and Techniques for Vacuum Devices, New York:Reinhold, 1967, pp. 494. 
Table 1. Life Test Parameters

\begin{tabular}{l|c|c|c|c|c}
\hline \hline \multirow{2}{*}{ Parameter } & \multicolumn{5}{c}{ Value } \\
\cline { 2 - 6 } & Initial & Mean & Min. & Max. & Final \\
\hline \hline Anode Voltage, V & 11.0 & 12.9 & 11.0 & 16.2 & 13.5 \\
\hline Emission Current, A & 12.0 & 12.0 & 12.0 & 12.0 & 12.0 \\
\hline Xenon Flow Rate, sccm & 4.22 & 4.33 & 3.77 & 5.22 & 4.70 \\
\hline $\begin{array}{l}\text { Cathode Tip Temperature, }{ }^{\circ} \mathrm{C} \text { - Dis- } \\
\text { appearing Filament Pyrometer }\end{array}$ & 1,350 & 1,260 & 1,179 & 1,368 & 1,358 \\
\hline \hline
\end{tabular}

Table 2. Hollow Cathode Phenomena

\begin{tabular}{|c|c|c|c|}
\hline Location & Phenomena & Observations & Impact \\
\hline $\begin{array}{l}\text { Orifice } \\
\text { Plate } \\
\text { Surface }\end{array}$ & $\begin{array}{l}\text { Erosion and } \\
\text { Deposition }\end{array}$ & $\begin{array}{l}\text { Exterior surface textured. } \\
\text { Tungsten deposition apparent on interior } \\
\text { surface. } \\
\text { Negligible change in plate thickness. } \\
\text { Electron-beam weld between tube and plate } \\
\text { intact. Weld bead appears to be removed. }\end{array}$ & Negligible. \\
\hline Orifice & Erosion & $\begin{array}{l}\text { Orifice diameter increased by } 14 \% \pm 2 \% \text { at } \\
\text { pass-through. }\end{array}$ & $\begin{array}{l}\text { Increases in orifice size } \\
\text { consistent with required } \\
\text { flow increases. }\end{array}$ \\
\hline $\begin{array}{l}\text { Orifice } \\
\text { Channel \& } \\
\text { Chamfer }\end{array}$ & Erosion & $\begin{array}{c}\text { Orifice channel diameter increases by } \sim 29 \% \\
\text { towards exterior end. } \\
\text { Chamfer intact but edges eroded. }\end{array}$ & $\begin{array}{l}\text { Not significant: expected } \\
\text { from past tests. }\end{array}$ \\
\hline \multirow{3}{*}{$\begin{array}{l}\text { Electron } \\
\text { Emitter }\end{array}$} & $\begin{array}{l}\text { Tungsten } \\
\text { Deposition }\end{array}$ & $\begin{array}{l}\text { Tungsten grains formed at dowristream end } \\
\text { of emitter, covering surface. } \\
\text { Smaller W flakes observed on oi her emitter } \\
\text { surfaces. }\end{array}$ & $\begin{array}{l}\text { Downstream deposition } \\
\text { not significant because } \\
\text { of degraded emission } \\
\text { surface. } \\
\text { Upstream deposition } \\
\text { expected to contribute to } \\
\text { tungstate formation. }\end{array}$ \\
\hline & $\begin{array}{l}\text { Ba-layer } \\
\text { formations }\end{array}$ & $\begin{array}{l}\mathrm{Ba}_{2} \mathrm{CaWO}_{6} \text { and } \mathrm{BaWO}_{4} \text { contained in layers } \\
\text { covering } \sim 70 \% \text { of upstream end of emitter. } \\
\text { Layer up to } 90 \mu \mathrm{m} \text { thick at upstream end. }\end{array}$ & $\begin{array}{l}\text { Results in degraded } \\
\text { emission operation by } \\
\text { inhibiting Ba release and } \\
\text { surface Ba-O formations. }\end{array}$ \\
\hline & $\begin{array}{l}\text { Interior } \mathrm{Ba} \\
\text { content }\end{array}$ & $\begin{array}{l}\text { Copious amounts of Ba present in } \& \text { on } \\
\text { emitter. However, amount of available Ba is } \\
\text { unknown. }\end{array}$ & $\begin{array}{l}\text { Emission degraded if } \mathrm{Ba} \\
\text { is locked up in inert } \\
\text { compounds. }\end{array}$ \\
\hline $\begin{array}{l}\text { Cathode } \\
\text { Tube }\end{array}$ & Unknown & $\begin{array}{c}\text { Preferential removal of Mo from tube } \\
\text { exterior surface. Final structure of tube } \\
\text { porous } \\
\end{array}$ & $\begin{array}{l}\text { Not significant for this } \\
\text { test. }\end{array}$ \\
\hline Heater Foil & $\begin{array}{l}\text { Erosion/ } \\
\text { Thermal } \\
\text { Degradation }\end{array}$ & $\begin{array}{l}\text { Edges and outer foil layer erc ded and } \\
\text { embrittled. Remaining portion :till firmly } \\
\text { attached to heater. }\end{array}$ & Not signilicant for HCA. \\
\hline
\end{tabular}




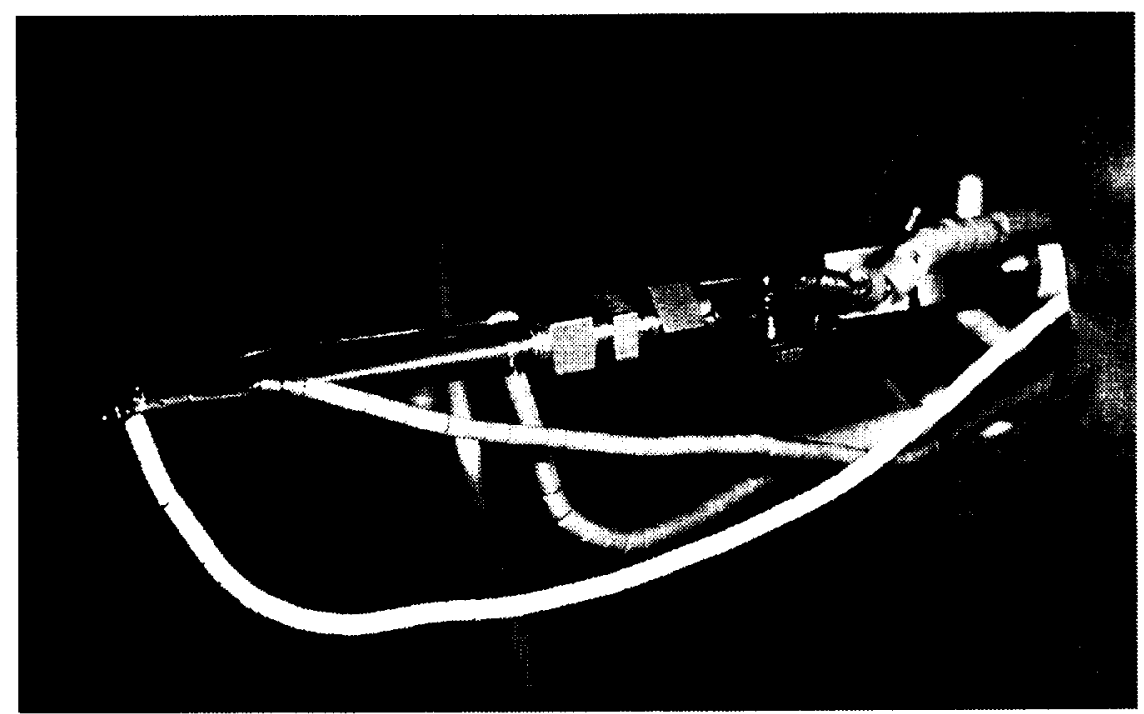

Figure 1. Photograph of cathode with diode in test configuration.

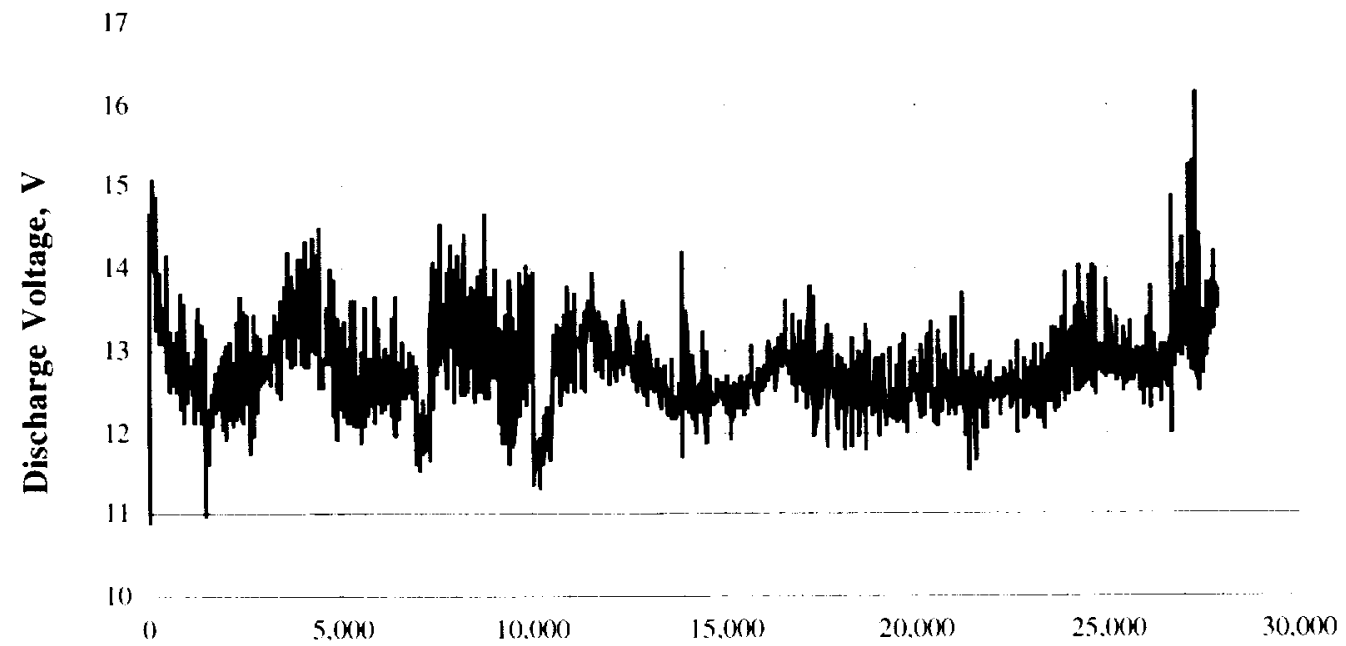

Test Time, hours

Figure 2. Discharge voltage as a function of test time. Voltage measured at vacuum test flange with digital voltmeter. 


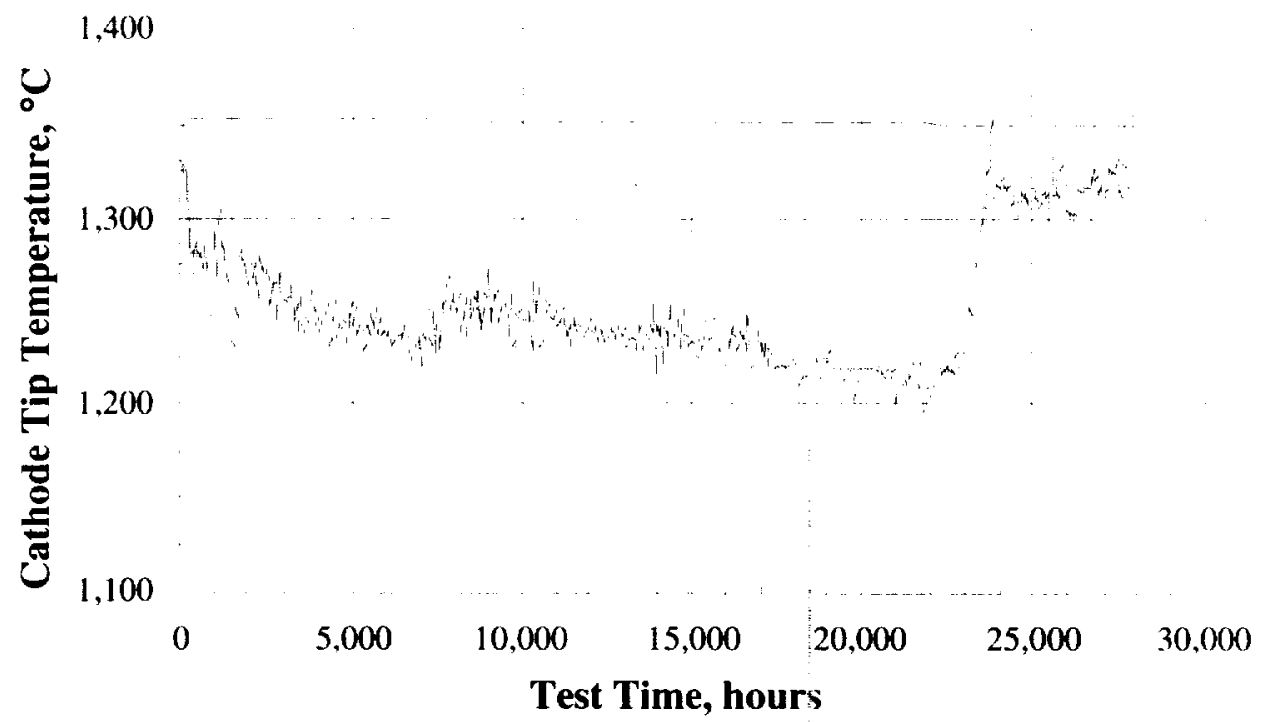

Figure 3. Cathode temperatures as function of test time. Temperatures measured with a disappearing filament pyrometer. The dashed line indicates the maximurn temperature limit for the life test.

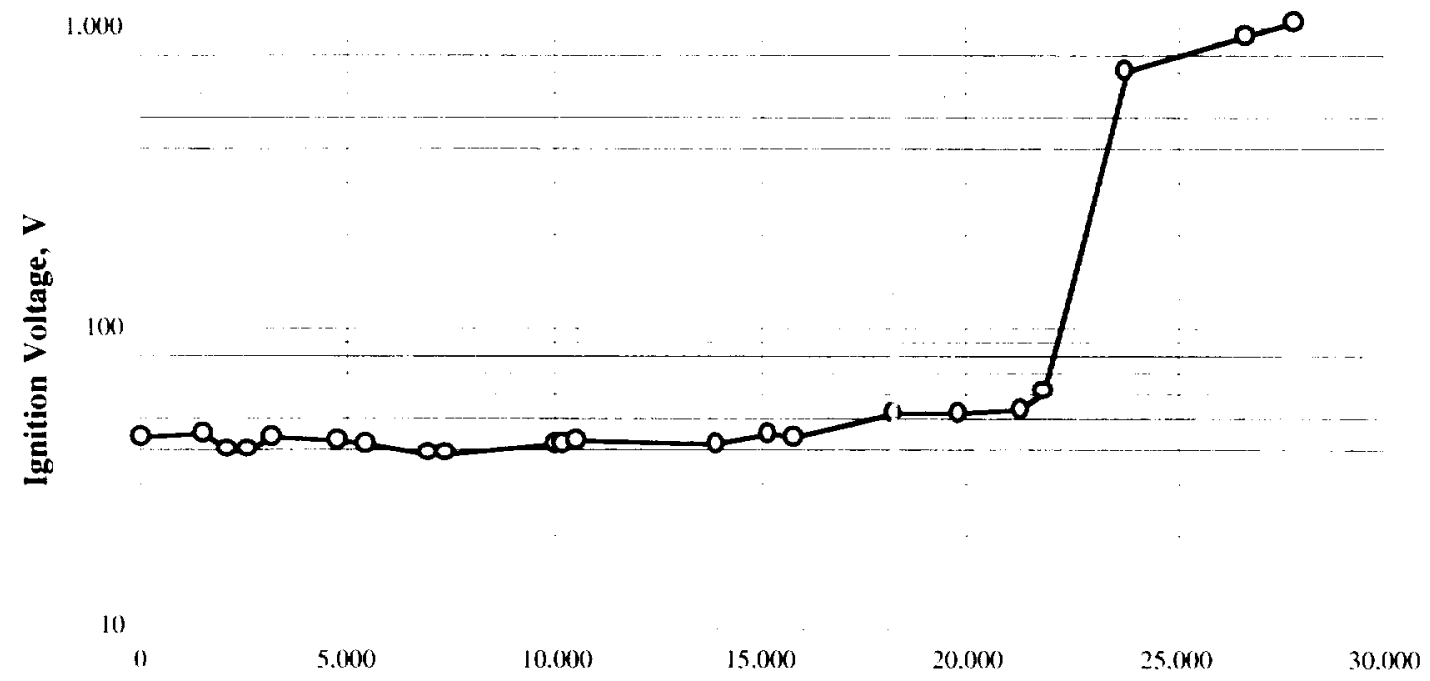

Test Time, hours

Figure 4. Ignition voltage as function of test time. Voltage measured at vacuum test flange with digital voltmeter. 

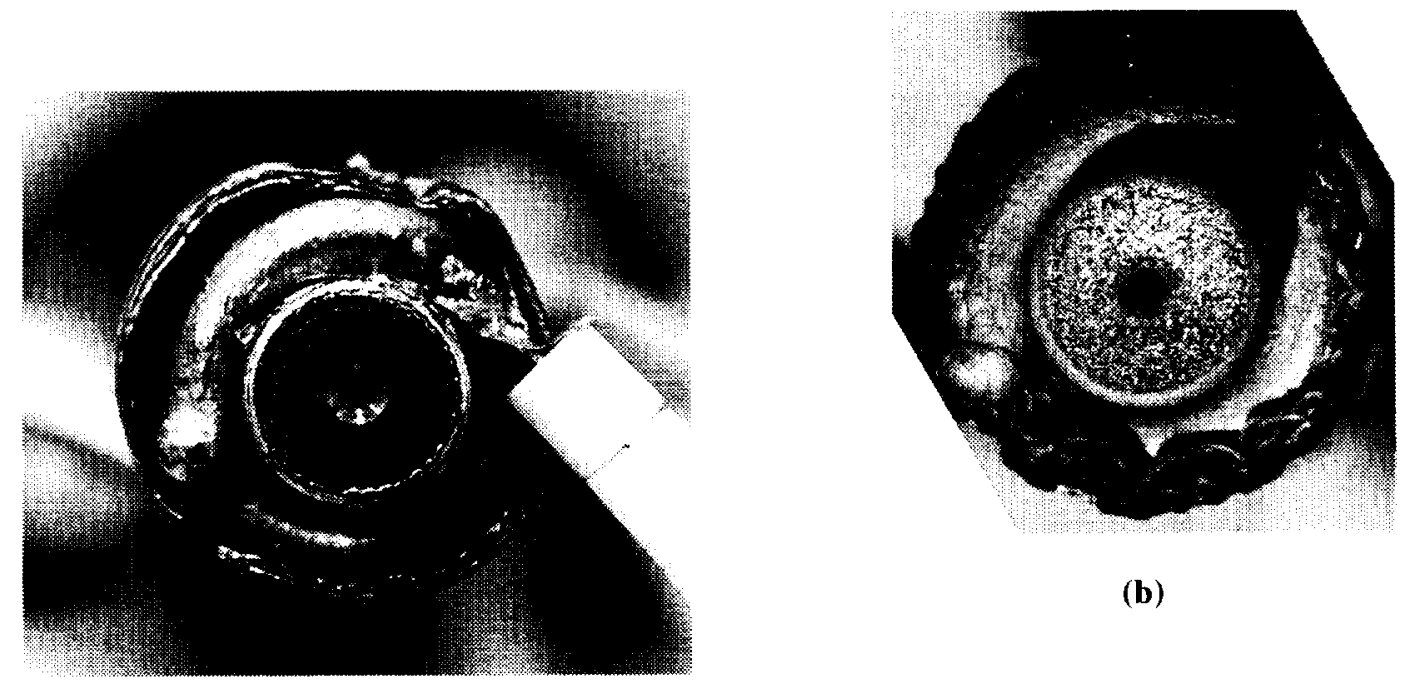

(b)

(a)

Figure 5. Cathode orifice plate: (a) Pre-test condition. (b) Post-test condition.

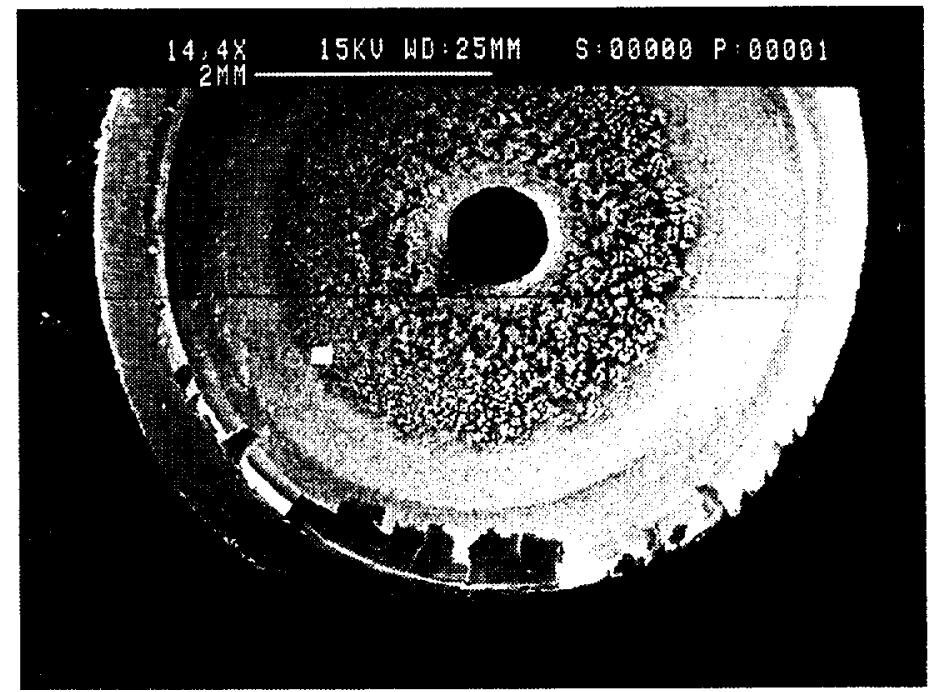

Figure 6. Micrograph of orifice plate interior surface. 


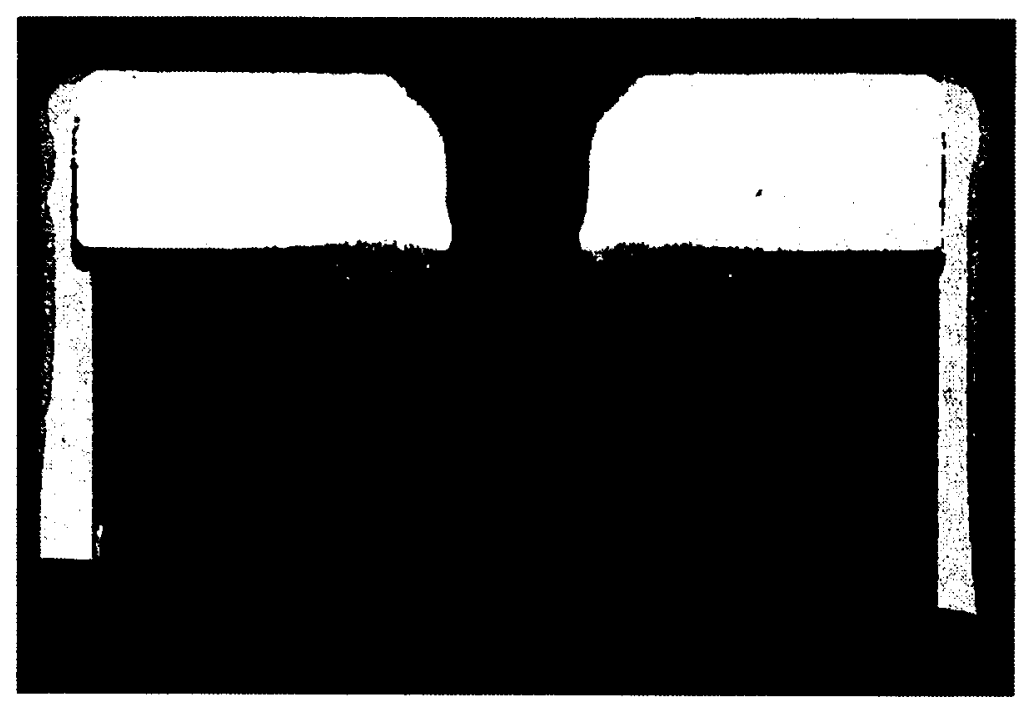

Figure 7. Metallograph of cathode tip cross-section. The exterior of the cathode is at the top of the photograph.

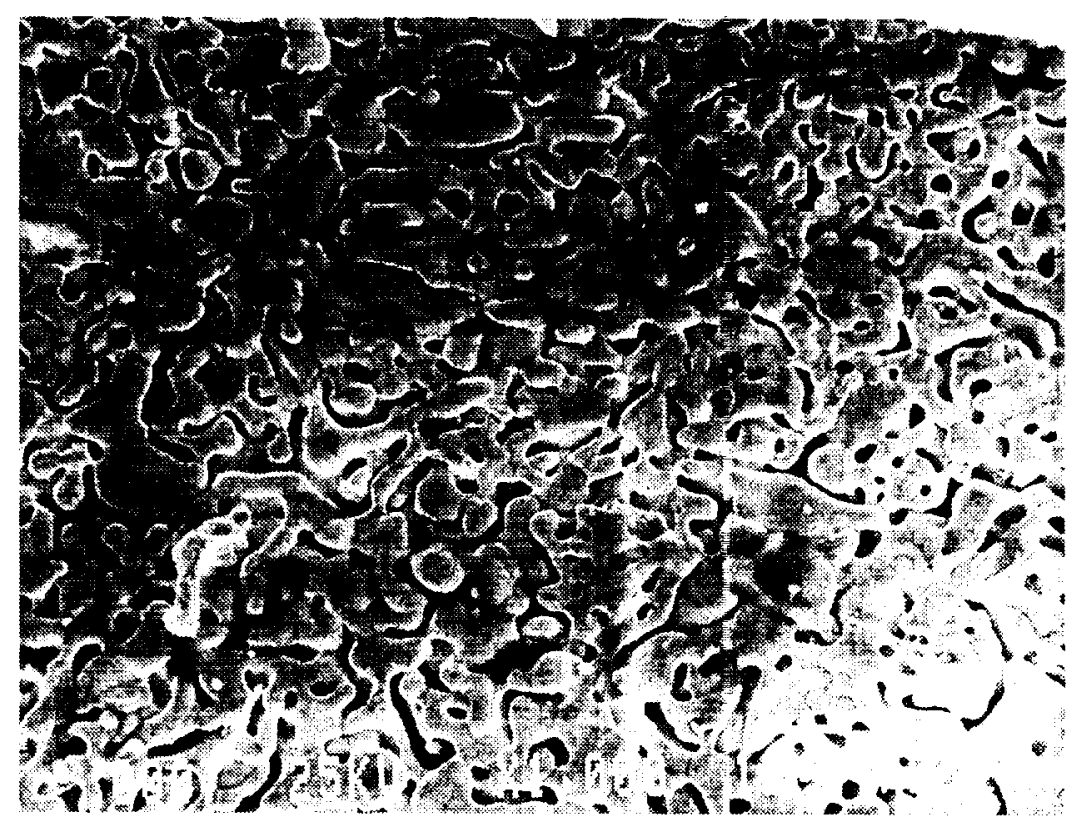

Figure 8. Micrograph of exterior surface of cathode tube. 
EI Ba-based Coating - partial to full coverage

Q5. Impregnate-derived Fill

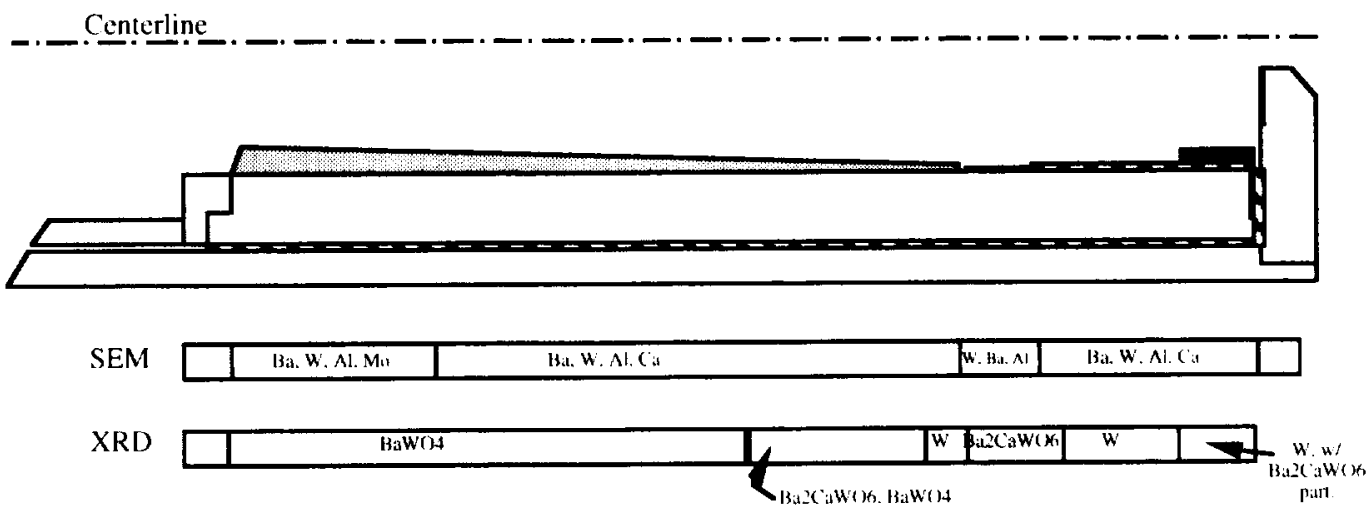

Figure 9. Schematic of observed phenomena on post-test electron emitter. The emitter, orifice plate, and deposition geometry are not to scale.

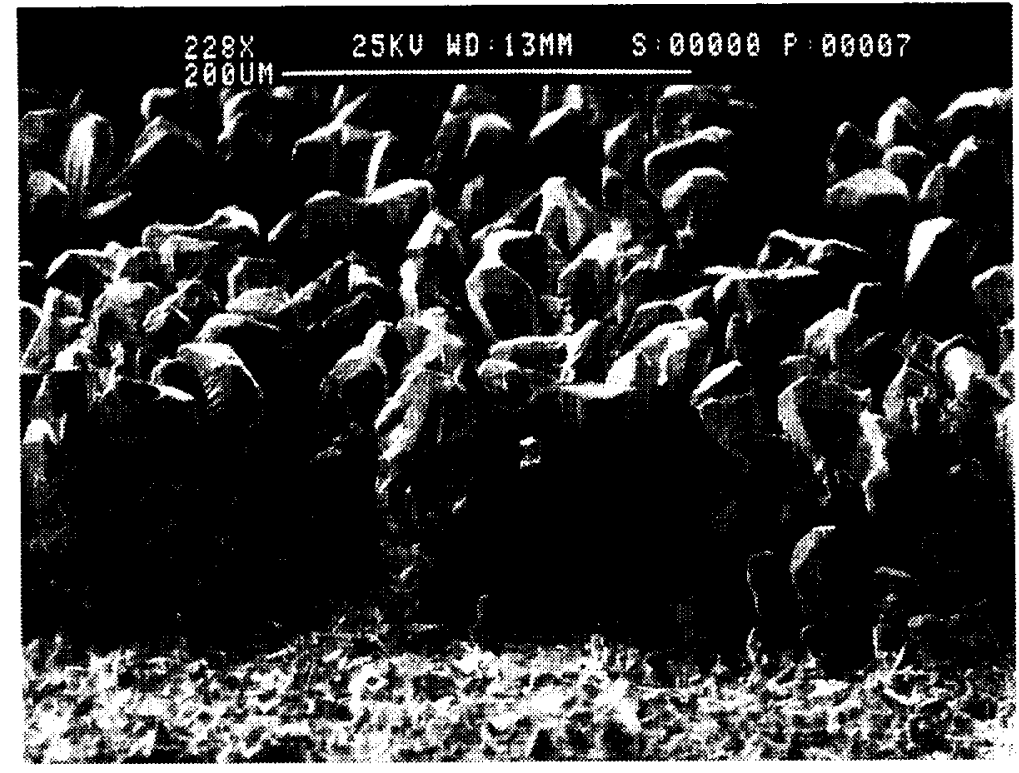

Figure 10. Tungsten deposition on the downstream end of the electron emitter. 


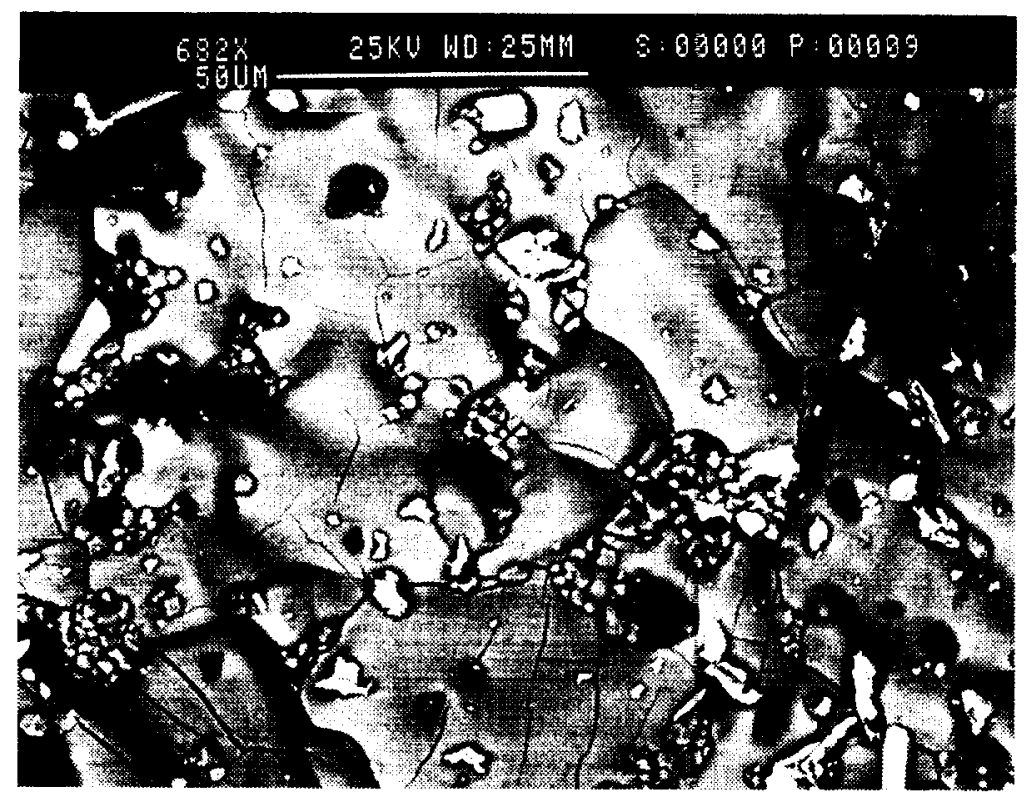

Figure 11. Micrograph of amorphous layers on upstream portion of electron emitter surface. This area was approximately $7.6 \mathrm{~mm}$ from the downstream end of the electron emitter.

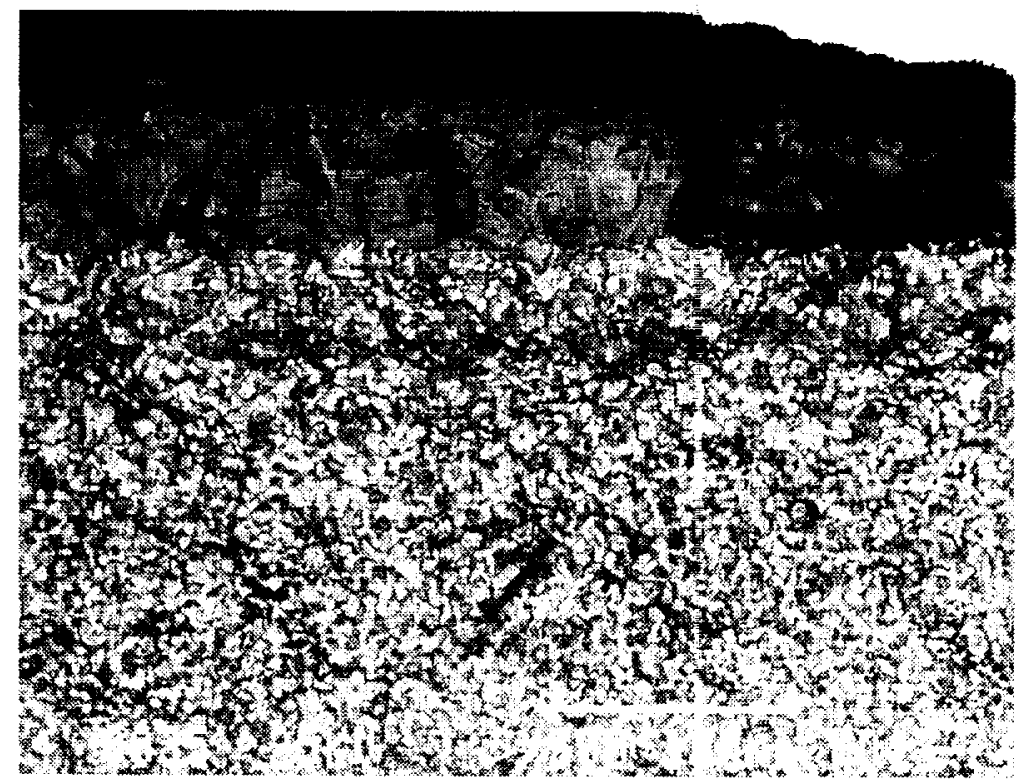

Figure 12. Edge view of amorphous layers on electron emitter sur face. This micrograph was taken near the upstream end of the emitt $\cdot r$. 
Public reporting burden tor this collection of information is estimated to average 1 hour per response, including the time for reviewing instructions. searching existing data sources, gathering and maintaining the data needed, and completing and reviewing the collection of intormation. Send comments regarding this burden estimate or any other aspect of this collection of information, including suggestions for reducing this burden, 10 Washington Headquarters Services, Directorate for Information Operations and Reports, 1215 Jefferson Davis Highway. Suite 1204, Arlington. VA 22202-4302, and to the Office of Management and Budget, Paperwork Reduction Project (0704-0188), Washington, DC 20503.

\begin{tabular}{|l|l|l|}
\hline 1. AGENCY USE ONLY (Leave blank) & $\begin{array}{c}\text { 2. REPORT DATE } \\
\text { October } 1998\end{array}$ & $\begin{array}{r}\text { 3. REPORT TYPE AND DATES COVERED } \\
\text { Final Contractor Report }\end{array}$ \\
\hline
\end{tabular}

\section{TITLE AND SUBTITLE}

Destructive Evaluation of a Xenon Hollow Cathode After a 28,000 Hour Life Test
WU-022-00-00-00

NAS. $3-98008$

Timothy R. Sarver-Verhey

7. PERFORMING ORGANIZATION NAME(S) AND ADDRESS(ES)

8. PERFORMING ORGANIZATION REPORT NUMBER

Dynacs Engineering Company, Inc.

Brook Park, Ohio 44135

$E-11410$

\section{SPONSORING/MONITORING AGENCY NAME(S) AND ADDRESS(ES)}

National Aeronautics and Space Administration

Lewis Research Center

Cleveland, Ohio 44135-3191
10. SPONSORING/MONITORING AGENCY REPORT NUMBER

NASA CR-1998-208678

AIAA $98-3482$

\section{SUPPLEMENTARY NOTES}

Prepared for the 34th Joint Propulsion Conference and Exhibit cosponsored by AIAA. ASME. SAE. and ASEE, Cleveland, Ohio, July 13-15, 1998. Project Manager, Sandra Hardy, Systems Engineering Division. NASA Lewis Research Center, organization code 7830, (216) 433-2278.

Unclassified - Unlimited

Subject Categories: 20 and 75

Distribution: Nonstandard

This publication is available from the NASA Center for AeroSpace Information, (301) 621-0390)

\section{ABSTRACT (Maximum 200 words)}

The International Space Station (ISS) plasma contactor system requires a hollow cathode assembly (HCA) with a lifetime of at least 18,000 hours. In order to demonstrate the lifetime capability of the HCA, a series of hollow cathode wear tests was performed which included a life test operated at the maximum current of the HCA. This test sought to verify hollow cathode lifetime capability and contamination control protocols. This hollow cathode accumulated 27,800 hours of operation before it failed during a restart attempt. The cathode was subsequently destructively analyzed in order to determine the failure mechanism. Microscopic examination of the cathode interior determined that relatively small changes in the cathode physical geometry had occurred and barium tungstates, which are known to limit the emission process, had formed over a majority of the electron emitter surface. Because the final state of the insert was consistent with expected impregnate chemistry, the hollow cathode was believed to have reached the end of its usable life under the test conditions.

\section{SUBJECT TERMS}

Hollow cathode; Electron emission; Plasma contactor; Dispenser cathode; Spacecraft charging

\begin{tabular}{|c|c|}
\hline $\begin{array}{c}\text { 17. SECURITY CLASSIFICATION } \\
\text { OF REPORT }\end{array}$ & $\begin{array}{c}\text { 18. SECURITY CLASSIFICATION } \\
\text { OF THIS PAGE } \\
\text { Unclassified }\end{array}$ \\
Unclassified
\end{tabular}

NSN 7540-01-280-5500

Unclassified $\quad$ Unclassified

\begin{tabular}{|l|} 
15. NUMBER OF PAGES \\
20 \\
\hline $\begin{array}{c}\text { 16. PRICE CODE } \\
\text { A03 }\end{array}$ \\
20. LIMITATION OF ABSTRACT \\
\end{tabular}

Standard Form 298 (Rev. 2-89)

Prescribed by ANSI Std. 239-18 298-102 
